JGG 2021;69:258-261

doi: $10.36150 / 2499-6564-N 454$

\title{
Comprehensive Geriatric Assessment (CGA) in patients with DM
}

\author{
Angelo Scuteri
}

Department of Medical Sciences and Public Health, University of Cagliari, Cagliari, Italy; Italian

Society of Gerontology and Geriatrics, Florence, Italy

\section{RECOMMENDATIONS}

The Comprehensive Geriatric Assessment (CGA) is an indispensable tool that can help the decision-making process for geriatric DM patients. Certain aspects described in the position statement of the American Diabetes Association and the European Association for the Study of Diabetes ${ }^{1}$ should be applied in the daily clinical practice of these patients:

A. Conduct a standardized assessment of the patient's functioning and the impact of care on functional independence (or disability), which should be repeated periodically (at least once a year in geriatric patients - if possible, every six months).

B. Expand the diagnostic framework to identify and eliminate factors arising from comorbidities or the patient's social situation that also affect the control of cardiometabolic risk factors $(\mathrm{HbA} 1 \mathrm{c}$, arterial pressure, LDL cholesterol) and/or undergo regular, scheduled monitoring.

C. Define therapeutic objectives and standards of care, highlighting the inclusion of functional outcomes as the main aims of the care process of geriatric patients.

Received: July 30, 2021

Accepted: September 16, 2021

\section{Correspondence \\ Angelo Scuteri \\ Department of Medical Sciences and Public \\ Health, University of Cagliari, via Università 40, \\ 09124 Cagliari, Italy \\ E-mail: angelo.scuteri@unica.it}

How to cite this article: Scuteri A. Comprehensive Geriatric Assessment (CGA) in patients with DM. Journal of Gerontology andGeriatrics2021;69:258-261.https://doi. org/10.36150/2499-6564-N454

(C) Copyright by Società Italiana

di Gerontologia e Geriatria (SIGG)

\section{(c) (1) () (}

\section{OPEN ACCESS}

This is an open access article distributed in accordance with the CC-BY-NC-ND (Creative Commons Attribution-NonCommercial-NoDerivatives 4.0 International) license. The article can be used by giving appropriate credit and mentioning the license, but only for non-commercial purposes and only in the original version. For further information: https://creativecommons.org/licenses/by-nc-nd/4.0/deed.en
D. Maintain remaining functions and delay the occurrence of disability by slowing down functional decline as this is essential for a "patientcentered' care model ${ }^{2,3}$, which also takes into account the needs of caregivers, and helps to sustain national health services by reducing the costs of inappropriate care.

E. All geriatric DM patients should undergo to at least one Comprehensive Geriatric Assessment annually including evaluation of:

- motor functioning (recommended scales: Tinetti scale of Gait and Balance and Studenski et al's 4 meter gait speed);

- cognitive functioning (recommended scale: Mini-Mental Status Examination (MMSE));

- tone and sound;

- comorbidities and multimorbidity (recommended scale: Cumulative Illness Rating Scale (CIRS));

- drug appropriateness (recommended scales: STOPP and START criteria);

- functional status (recommended scales: Activities of Daily Living (ADL), Instrumental Activities of Daily Living (IADL), Barthel Index);

- social support.

F. Evaluation of the different domains should be carried out using standardized and quantitative (e.g., with numerical scores) data collection tools to enhance communication of results between various professionals, allow for longitudinal assessment of changes in the different domains (natural history and/or effectiveness of interventions), as well as to help plan resource and service utilization. 
G. Different domains can be selected for evaluation depending on the care setting (e.g., DM patients over 75 years of age would likely be evaluated in an outpatient clinic) and available resources, both in terms of time and staff.

$H$. The outcome of this initial CCGA should help to identify individual needs to help the application of a personalized medicine approach, and the information can provide guidance on which components of the CGA need to be repeated or added in subsequent evaluations.

I. The appendix provides brief operational instructions on how to administration and interpret the scales used to assess the above components.

\section{STRENGTH OF THE RECOMMENDATIONS}

The quality of the evidence is moderate. Recommendations are supported by published evidence and best practice (supported by expert opinion).

\section{SUPPORTING EVIDENCE}

See appendix.

\section{AREAS OF UNCERTAINTY AND FUTURE PERSPECTIVES}

There are not enough studies with formal and systematic adoption of a standardized CGA in older DM subjects targeting cardiometabolic and functional outcomes. Whether "real world" dataset (i.e., registries) can help to bridge this gap or whether telemedicine/teleassistance can support and facilitate routine adoption of CGA in older DM patients remains a hot topic.

\section{APPENDIX}

Diabetes management in geriatric patients is often a challenge for physicians because patients usually have coexisting multiple pathological, psychological, and social conditions that may influence the evolution and treatment of the disease ${ }^{1}$.

The 2020 American Diabetes Association (ADA) "Older Adults: Standards of Medical Care in Diabetes" recommends a multidimensional approach for geriatric DM patients ${ }^{4}$. Comprehensive Geriatric Assessment (CGA) has been proposed as a useful tool for identifying the different problems that can affect the efficacy of clinical interventions, for example, lack of patient
Table I. (ADA 2020). Recommendations

Consider the assessment of medical, psychological, functional (selfmanagement abilities), and social geriatric domains in older adults to provide a framework to determine targets and therapeutic approaches for diabetes management. $\mathrm{B}$

Screen for geriatric syndromes (i.e., polypharmacy, cognitive impairment, depression, urinary incontinence, falls, and persistent pain) in older adults as they may affect diabetes self-management and diminish quality of life. $B$

compliance ${ }^{5,6}$, which can lead to further deterioration in glucose metabolism (Tab- I) ${ }^{7}$.

However, the ADA's brief and simple recommendations, described in Table I in their original wording, have a broader clinical impact. For example, the ADA's recommendations explicitly indicate the need for annual screening of cognitive functioning without indicating the most suitable tests to use ${ }^{4}$. However, the identification of cognitive decline could be used as a "stratifying factor": the management of geriatric DM patients varies considerably depending on whether they have cognitive impairment. This is because cognitive impairment in geriatric DM patients can affect their ability to self-monitor, self-manage, and self-administer drugs ${ }^{8,9}$.

\section{BRIEF OPERATIONAL INSTRUCTIONS ON HOW TO ADMINISTRATION AND INTERPRET THE SCALES USED TO ASSESS COMPONENTS OF THE CGA}

The recommended scales below are not restricted by Copyright and can, therefore, be easily used in clinical practice. Other high quality, validated assessment scales are available, but the ones recommended here are the scales that are most commonly used in the geriatric population.

\section{Evaluation of motor functions}

\section{Tinetti scale - Gait and Balance ${ }^{10}$}

The Tinetti scale is specifically indicated for assessing fall risk. The maximum score is 28 . Scores $\leq 1$ indicate that the patient is unable to walk; between 2 and 19 indicates that the patients is at risk of falling; $\geq 20$ suggests the patient is ambulatory and has a low risk of falling. The quality of performance is assessed but speed is not considered to be particularly relevant. During this test, the patient can use any assistive devices (e.g., walking stick, crutches, zimmer frame) that they normally use. The scale can be used to identify patients who need close observation or rehabilitation programs as well as to evaluate the effectiveness or adverse side effects of therapy and rehabilitation programs. It can be done by simply observing the patient when they get up to enter the examination room, thus saving time. 


\section{Studenski et al's $\mathbf{4}$ meter gait speed ${ }^{11}$}

The walking-speed test is simple, quick, reproducible, cost-effective, feasible, and can also be administered by non-medical personnel. A 5-7 meter corridor is needed to conduct the test. The patient is instructed to walk normally, and the assessor records the time taken to travel a four meter distance. A speed of $0.8 \mathrm{~m} / \mathrm{sec}(5$ sec execution time) is the normal cutoff, while $<0.6 \mathrm{~m} /$ sec (approximately $7 \mathrm{sec}$ execution) indicates a deficit in motor function. Studies suggest that up to 8 seconds is an acceptable speed for geriatric patients.

\section{Assessment of cognitive functioning}

\section{Mini-Mental Status Examination (MMSE) ${ }^{12}$}

The MMSE is a useful, basic screening and evaluation tool (also for follow-ups). It takes 10-15 minutes to administer. The maximum score is 30 (indicating no cognitive deficits). A cut off of 23-24 is used to identify cognitive impairment. However, as age and educational level have been shown to significantly affect performance, a score of 21 is a more suitable cut off for cognitive impairment in people over the age of 75 who have low levels of education. A diagnosis of dementia should be carried out in a specialized clinic (geriatric or neurological). It has been recommended for screening inoteh common conditions, such as hypertension ${ }^{13}$.

\section{Mood assessment: Geriatric Depression Scale (GDS) (15 items) ${ }^{14}$}

The GDS is one of the most commonly used scales for evaluating depressive symptoms in geriatric patients and can also be administered in patients mild to moderate dementia (it is not recommended for use in patients with MMSE < 15). It is a 15-item instrument, which excludes certain somatic or psychotic symptoms. Answers are binary (yes/no), making it easier to use in older patients with cognitive deficits.

The total score ranges from 0 (no sign of depressive symptoms) to 15 (severe depression) with an intermediate status of between 6 and 9 points indicating a reasonable possibility of mild depression that should be evaluated further by a specialist or qualified psychologist.

\section{Assessment of comorbidities}

\section{Cumulative IIIness Rating Scale (CIRS) ${ }^{15}$}

No complex or specific tools are needed for the CIRS scale as it can be adequately assessed by taking a medical history and objective clinical examination. Based on the clinical history and objective and symptomatic examination presentation, the physician defines the patient's level of severity (clinical and/or functional) in 14 categories of systems and organs, each one scoring from 1 (absent) to 5 (life-threatening).

There are two indices:

- the severity index, which results from the average of the scores of the first 13 categories (excluding the category of psychiatric/behavioral diseases);

- the comorbidity index, which represents the number of categories in which a score of 3 or more is obtained (excluding the category of psychiatric/ behavioral diseases).

\section{Assessment of potentially inappropriate drug prescriptions}

Screening Tool of Older People's Prescriptions (STOPP) and Screening Tool to Alert to Right Treatment (START) criteria

The system for assessing appropriateness of drug prescription is based on two types of criteria: classes of drugs not to be prescribed in older patients (STOPP: Screening Tool of Older Person's Prescriptions and classes of drugs that should be prescribed (START: Screening Tool to Alert doctors to Right Treatment). Applying the STOPP/START criteria as a screening during every clinical examination provides the opportunity to review the patient's drug therapy and detect prescription errors or omissions.

According to the 2014 version, there are STOPP 80 criteria (55 drugs or classes of drugs to avoid for certain pathologies, 9 drug combinations to avoid, 7 indications on treatment duration, 2 on dosages, and 7 dosage indications in case of kidney failure) while there are 34 START criteria, with explicit indications for the most common diseases affecting older persons in terms of drug-disease and drug-drug interactions, drug duplication, and under-prescribing.

\section{Assessment of functioning}

The most commonly used instruments use an indirect assessment of functioning (i.e., through interviews with family members). For an initial clinical assessment for $D M$, the use of ADL, IADL or Barthel Index is sufficient because they are simple and quick to administer.

\section{Activities of Daily Living (ADL) scale ${ }^{16}$}

The ADL accurately assesses six basic daily activities: bathing, dressing, toileting, transference, continence (urinary and fecal), and eating. Scoring is dichotomous (dependent/independent), which makes this tool less flexible than the Barthel Index (see below).

Instrumental Activities of Daily Living (IADL) ${ }^{17}$

This instrument assesses the patient's ability to perform activities that older people usually carry out and are considered necessary for maintaining independence. The scale is usually scored dichotomously, with only two possible responses for each item (independent $=1$ and dependent $=0$ ). However, the individual items should be taken into account to create an accurate profile of the person's level of disability. It is important to consider that selected activities that the patient never carried out even when they were 
fully independent, such as doing laundry for men because it was considered 'predominantly carried out by women'. For this reason, some printout of IADL include the option "not applicable" in addition to the $0 / 1$ scoring described above.

\section{Barthel Index ${ }^{18}$}

This index provides a score that indicates the patient's abilities in feeding, personal toileting, bathing, dressing and undressing, getting on and off a toilet, bladder and bowel control, moving from wheelchair to bed and returning, walking on a level surface, and ascending and descending stairs. There is a specific maximum score for each function (e.g., 5 for bathing, 15 for walking on a level surface). In addition, the score differs depending on whether the patient performs a function on their own or if they need help (even partially) from others. The maximum score is 100 , indicating independence in all basic activities of daily life.

\section{Ethical consideration}

None.

\section{Acknowledgement}

None.

\section{Funding}

None.

\section{Conflict of interest}

The Author declare no conflict of interest.

\section{References}

1 Inzucchi SE, Bergenstal RM, Buse JB, et al. Management of hyperglycemia in type 2 diabetes, 2015: a patient-centered approach: update to a position statement of the American Diabetes Association and the European Association for the Study of Diabetes. Diabetes Care 2015;38:140-149. https://doi.org/10.2337/dc14-2441

2 Reuben DB, Tinetti ME. Goal-oriented patient care: an alternative health outcomes paradigm. N Engl J Med 2012;366:7779. https://doi.org/10.1056/nejmp1113631

3 Working Group on health outcomes for older persons with multiple chronic conditions. Universal health outcome measures for older persons with multiple chronic conditions. J Am Geriatr Soc 2012;60:2333-2341. https://doi. org/10.1111/j.1532-5415.2012.04240.x

4 American Diabetes Association. Older adults: standards of medical care in diabetes, 2020. Diabetes Care 2020;43(Suppl 1):S152-S162. https://doi.org/10.2337/dc20-s012
5 Felace G, Boemi M, Candido R, et al. L'approccio clinico assistenziale al paziente anziano con diabete mellito tipo 2. Gruppo AMD Diabete nell'anziano, 10 maggio 2017 (https:// aemmedi.it/wp-content/uploads/2016/09/App_clin_ass_anziano_DM2_maggio17.pdf).

6 Fiore V, Boemi M. Riconoscere la fragilità: gli strumenti della valutazione multidimensionale. II Giornale di AMD 2013;16, S1:11-14 (https://www.jamd.it/wp-content/ uploads/2017/02/2013_1_S_3.pdf).

7 Sinclair AJ, Abdelhalfiz AH, Rodriguez-Manas L. Frailty and sarcopenia - newly emerging and high impact complication of diabetes. J Diabetes Complications 2017;31:1465-1473. https://doi.org/10.1016/j.jdiacomp.2017.05.003

8 Barbagallo M, Dominguez LJ. Type 2 diabetes mellitus and Alzheimer's disease. World J Diabetes 2014;5:889-893. https://doi.org/10.4239/wjd.v5.i6.889

9 American Geriatrics Society expert panel on care of older adults with diabetes mellitus; Moreno G, Mangione CM, Kimbro L, et al. Guidelines abstracted from the American Geriatrics Society Guidelines for improving the care of older adults with diabetes mellitus: 2013 update. J Am Geriatr Soc 2013;61:2020-2026. https://doi.org/10.1111/jgs.12514

10 Tinetti ME. Performance-oriented assessment of mobility problems in elderly patients. J Am Geriatr Soc 1986;34:119-126. https://doi.org/10.1111/j.1532-5415.1986.tb05480.x

11 Studenski S, Perera S, Wallace D, et al. Physical performance measures in the clinical setting. J Am Geriatr Soc 2003;51:314322. https://doi.org/10.1046/j.1532-5415.2003.51104.x

12 Scuteri A, Benetos A, Sierra C, et al. Routine assessment of cognitive function in older patients with hypertension seen by primary care physicians: why and how-a decision-making support from the working group on 'hypertension and the brain' of the European Society of Hypertension and from the European Geriatric Medicine Society. J Hypertens 2021;39: 90-100.

13 Folstein MF, Folstein S, McHugh PR. "Mini-mental state". A practical method for grading the cognitive state of patients for the clinician. J Psychiatr Res 1975;12:189-198. https://doi. org/10.1016/0022-3956(75)90026-6

14 Sheikh JI, Yesavage JA. Geriatric Depression Scale (GDS): recent evidence and development of a shorter version. In: Clinical gerontology: a guide to assessment and intervention, TL Brink Ed. Binghamton, NY: Haworth Press 1986, pp. 165-173.

15 Parmalee PA, Thuras PD, Katz IR, et al. Validation of the cumulative illness rating scale in a geriatric residential population. J Am Geriatr Soc 1995;43:130-137. https://doi. org/10.1111/j.1532-5415.1995.tb06377.x

16 Katz S, Ford AB, Moskowitz RW, et al. Studies of illness in the aged. The index of ADL: a standardized measure of biological and psychosocial functon. JAMA 1963;185:914-919. https:// doi.org/10.1001/jama.1963.03060120024016

17 Lawton MP, Brody EM. Assessment of older people: selfmaintaining and instrumental activities of daily living. Gerontologist 1969;9:179-186.

18 Mahoney FI, Barthel DW. Functional evaluation: the Barthel Index. Md State Med J 1965;14:61-65.

\author{
This statement is: \\ 囚 Recommendation (supported by published evidence) \\ $\square$ Best practice (supported by expert opinion)
}

Quality of the evidence (in the case of recommendation):
$\square$ Low
$\bigotimes$ Moderate
$\square$ High

